Abstracta Iranica

Revue bibliographique pour le domaine irano-aryen

Volume 37-38-39 | 2018

Comptes rendus des publications de 2014-2016

\title{
Leon Goldman. Rašn Yašt. The Avestan Hymn to 'Justice'
}

\section{Samra Azarnouche}

\section{(2) OpenEdition}

1 Journals

\section{Édition électronique}

URL : http://journals.openedition.org/abstractairanica/43037

DOI : 10.4000/abstractairanica.43037

ISBN : 1961-960X

ISSN : 1961-960X

Éditeur :

CNRS (UMR 7528 Mondes iraniens et indiens), Éditions de l'IFRI

Référence électronique

Samra Azarnouche, "Leon Goldman. Rašn Yašt. The Avestan Hymn to 'Justice' », Abstracta Iranica [En ligne], Volume 37-38-39 | 2018, document 11, mis en ligne le 30 décembre 2018, consulté le 28 septembre 2020. URL : http://journals.openedition.org/abstractairanica/43037 ; DOI : https://doi.org/ 10.4000/abstractairanica.43037

Ce document a été généré automatiquement le 28 septembre 2020

Tous droits réservés 


\title{
Leon Goldman. Rašn Yašt. The Avestan Hymn to 'Justice'
}

\author{
Samra Azarnouche
}

\section{RÉFÉRENCE}

Leon Goldman. Rašn Yašt. The Avestan Hymn to 'Justice'. Wiesbaden, Reichert, 2015, 257 p.

(Beiträge zur Iranistik 39).

1 Version révisée d'une thèse de doctorat soutenue en 2012 à la SOAS (Londres), cet ouvrage propose une édition classique de l'hymne dédié à Rašnu (Yašt 12) (moyenperse Rašn), divinité zoroastrienne connue dans la tradition post-avestique comme l'un des juges de l'au-delà. L'A. présente cette figure divine, sans équivalent indien et absent des Gā̧ā, comme celle qui, déjà dans l'Avesta, s'assure du maintien de la justice et de la rectitude, notamment par le recours à l'ordalie (avestique varah-).

2 Après une introduction portant principalement sur les aspects structurels et linguistiques du bref Yašt 12 (38 strophes) et sur la présentation de l'édition de texte (p. 1-23), l'ouvrage présente un portrait du dieu Rašnu à travers les différents corpus zoroastriens (p. 24-29) suivi par un chapitre sur la cosmographie mythique telle que ce texte la décrit (p. 33-49), - et qui consiste en l'énumération des zones terrestres et célestes habitées par cette divinité -, tout en la comparant avec des parallèles avestiques et moyen-perses (en particulier le Bundahišn). Le chapitre 4 (p. 50-86) analyse en profondeur la question de l'ordalie, rituel patronné par Rašnu et permettant de déterminer, par l'intermédiaire du surnaturel, la culpabilité ou l'innocence d'une personne. Le serment peut constituer une étape importante de ce rituel dont aucune description ne nous est parvenue. Nous savons toutefois qu'un lieu et un moment spécifique de la journée lui étaient destinés et qu'il pouvait impliquer une mise à l'épreuve corporelle, par exemple par un contact avec une matière brûlante (eau, métal, feu...). Le problème philologique de la célèbre expression *saukkantam hư⿱ «boire du souffre » est bien exposé, sans que l'A. ne prenne part au débat. On saluera 
l'effort d'avoir relevé les occurrences de l'ordalie (mp. war) dans la littérature moyenperse (auxquelles s'ajouterait un passage intéressant du Dēnkard III.169, DkD 693 = B 140 1.17-21, traduit par J. de Menasce 1973, p.179). Le dossier des épisodes hagiographiques (Ādurbād Mahraspandān, Zara9uštra, Ardā Wirāz) aurait pu tirer profit des récits périphériques aux textes zoroastriens (par ex. Siyāwaš dans le Shāhnāme, et Mar Aba et Pethion dans les textes chrétiens). Le dernier chapitre (p. 87-207) comprend l'édition critique de chaque strophe, suivie de sa traduction et d'un commentaire philologique. Un glossaire, une bibliographie, des index verborum et locorum complètent cet ouvrage qui tend à s'imposer comme une référence indispensable pour tout spécialiste des langues iraniennes anciennes et du zoroastrisme.

\section{AUTEURS}

\section{SAMRA AZARNOUCHE}

EPHE, Mondes iranien et indien 